to a degree only just sufficient to keep pace with the increasing length of the legs is suggested by the fact that the giraffe has to splay its forelimbs awkwardly to drink.

In this light, natural selection would seem to have operated continually in favour of increasing length of neck instead of intermittently during discontinuous periods of drought as necessitated by Darwin's theory.

Further, it seems to me that the leaf-eating habit of the giraffe is a concomitant of the development of the long neck and not the cause of it. It would seem reasonable to suppose that the ancestors of the giraffe were grass-eaters, and that with the lengthening of the neck a new source of food became available, resulting in a change of feeding habit. This contention is supported by the fact that giraffes eat grass if leaves are not available, and they thrive on hay in zoological gardens.

It may be argued that the giraffe's closest living relative, the okapi, is a leaf-eater, although its neck is no longer than that of a horse. The okapi, however, lives in dense forests where it has no option but to eat leaves.

I am indebted to Dr. Julian Huxley for valuable criticism of these views.

$$
\begin{aligned}
& \text { Daily Express, } \\
& \text { Fleet Street, } \\
& \text { London, E.C.4. } \\
& \text { April } 27 .
\end{aligned}
$$

${ }^{1}$ Darwin, C., “Origin of Species" (John Murray, 1859).

2 Brazier Howell, A., "Speed in Animals" (University of Chicago Press, 1944).

\section{An Aerobic Medium for Fungus Growth Studies}

THE aerobic nature of mushroom composts plays an essential part in the production of good mushroom crops, so that it is desirable, in laboratory growthexperiments on mushroom mycelium, to use an aerobic medium of known composition in which growth measurements can be made. The only fully aerobic medium of this nature in general use, so far as I am aware, is milled filter paper ${ }^{1,2,3}$. Unfortunately, this material loses its aerobic qualities when only a small amount of nutrient solution has been absorbed on it. A medium based on milled transparent cellulose shavings, dyed black to enable mycelial growth to be observed, has now been found to be more satisfactory, and is prepared as follows.

Boil cellulose film trimmings 'PT' (British Cellophane Co.) with a 0.5 per cent solution of carbide black $E$ (Clayton Aniline Co.) for 1-2 hr. until a good dye is obtained. Squeeze out the dye liquor, wash twice with tap water, and soak the clippings in $0.5 \mathrm{~N}$ hydrochloric acid for $1 \mathrm{hr}$. Drain and wash with tap water until the $p H$ rises to about 4 , then with distilled water until free from sulphate and chloride. Dry thoroughly at $50-70^{\circ} \mathrm{C}$. and immediately grind to pass the desired mesh screen. For general work, the 1-mm. screen may be used. A batch of material prepared in this way had 0.09 per cent ash, containing mainly calcium with some iron and aluminium, traces of magnesium and manganese and no copper or nickel. Mix with nutrient solution at the rate of $100 \mathrm{ml}$. of solution to $100 \mathrm{gm}$. of medium and pack lightly into 5 in. $\times \frac{3}{4}$ in. test-tubes.
Preliminary experiments with the mycelium of the cultivated white mushroom Psalliota campestris using 4 per cent malt nutrient solution gave excellent agreement in growth-rate between replicates when the tubes were inoculated with a $\frac{1}{8}$-in. layer of the cellulose medium, in which the fungus had previously been grown from pure culture. The initial linear growth-rate is independent of the density of the medium within the range $0 \cdot 7-1 \cdot 7 \mathrm{gm}$. of moist medium per $\mathrm{cm}$. tube-length (variations in density are obtained by milling through different screens). As the bottom of the tube is approached the growth. rate decreases more rapidly in the denser than in the lighter media. Differences in aeration rather than in the rates of diffusion of nutrients are thought to be responsible for this effect.

It is hoped to use this technique for the study of trace-element and growth-substance requirements of this organism, for comparing soluble and insoluble nutrients, and for further work on the influence of the grading of the medium on mycelial growth.

I wish to thank the Director of Research and the directors of the Mushroom Research Association, Ltd., for permission to publish this note.

\section{S. BurRows}

Mushroom Research Association, Ltd., Yaxley, Peterborough.

1 Pizer, N. H., J. Agric. Sci., 27, 349 (1937).

${ }^{2}$ Frear, D., Styer, J. F., and Haley, D. E., Plant Physiol., 3, 91 (1928). styer, J. F., Amer. J. Bot., 15, 246 (1928).

\section{Poisoning of Farm Animals by the Marsh Ragwort (Senecio aquaticus Huds.)}

Eleven Senecio spp. have been reported to occur in the British Isles ${ }^{1}$, but only a few of these contaminate pasture land to any appreciable extent. The common ragwort (Senecio jacoboea Linn.) has been incriminated in Britain ${ }^{2,3,4}$ and elsewhere ${ }^{5,8}$ as the cause of a fatal poisoning when eaten by livestock, known generally as 'seneciosis'. This condition, in cattle and horses, may either take a rapid fatal course with the liver showing acute necrosis, or a more lingering chronic type with liver cirrhosis as the main lesion.

Into one knackery in Pembrokeshire, during the period September 1947-August 1948, there was an intake of fifty-one animals diagnosed as having died of seneciosis. The predominant species infesting the pasture in this area is Senecio jacoboea Linn., and eradication trials using selective weed-killers have so far yielded promising results ${ }^{7}$. In Carmarthenshire, seneciosis, mainly in horses, has occurred on farms where the land is heavily infested with the marsh ragwort (Senecio aquaticus Huds.); there was no clear published evidence of the toxicity of this species ${ }^{8}$. Quantities of the plant were collected at the flowering. stage from fields in the area, and also from cured hay on the actual farms where losses had occurred. By the following procedure a crystalline Senecio alkaloid was isolated from $S$. aquaticus from both sources.

The plants were dried at $100^{\circ} \mathrm{C}$., milled, and the powder continuously extracted with ethanol. On evaporation of the ethanol fraction, the residue containing the total alkaloids, with much chlorophyll and dark resinous matter, was triturated with 2 per cent hydrochloric acid, and the clear brown acidsoluble fraction separated from tarry residues. Pig- 